
\title{
25 Research Suare \\ TEK Suppresses Lung Adenocarcinoma Cell Phenotypes by Interacting with miR-19a-3p
}

\section{Tao Peng}

Huangshi Central Hospital

Fan Yang

Huangshi Central Hospital

Zhanwen Sun

Huangshi Central Hospital

Jie Yan ( $\nabla$ hsszxyyxwk@163.com )

Huangshi Central Hospital https://orcid.org/0000-0003-2939-5395

Research article

Keywords: TEK, miR-19a-3p, lung adenocarcinoma, cell adhesion

Posted Date: July 1st, 2020

DOI: https://doi.org/10.21203/rs.3.rs-38816/v1

License: (c) (1) This work is licensed under a Creative Commons Attribution 4.0 International License.

Read Full License 


\section{Abstract}

Background: We identified TEK as a key gene that that participates in lung adenocarcinoma cell migration and adhesion, and miR-19a-3p a potential upstream regulator of TEK. Both TEK and miR-19a$3 p$ have been reported during lung cancer development. However, how TEK/miR-19a-3p interactome regulates lung adenocarcinoma remains unraveled. We herein aim to report a novel TEK/miR-19a-3p interactome in lung adenocarcinoma.

Methods: The mRNA and protein expression of TEK in tissues and cell lines were determined using qPCR and Western blot, respectively. CCK-8 assay, EDU assay, flow-cytometry cell apoptosis assay, scratch assay, and cell-to-extracellular matrix adhesion assay were performed to detect the proliferation, apoptosis, migration, and adhesion of A549 and H1975 cell lines.

ResultsखBoth mRNA and protein levels of TEK were down-regulated in tumor tissues and cell lines. Compared with the control, the transfection of TEK overexpression plasmids into H1975 and A549 cells led to the significant inhibition of cancerous phenotypes. On the other hand, miR-19a-3p promoted lung adenocarcinoma cancerous cell phenotypes by downregulating TEK.

Conclusions: TEK can be a potential LUAD tumor suppressor by interacting with miR-19a-3p. This novel interactome can be used as a novel therapy target for LUAD.

\section{Background}

Lung adenocarcinoma (LUAD), a main type of non-small cell lung cancer, has been increasingly determined to be correlated with several oncogenes or suppressors (Wang et al. 2017b). Approximately 1.5 million have died of lung adenocarcinoma worldwide (Daugaard et al. 2016, Siegel, Miller and Jemal 2015). The treatment of LUAD has achieved great progresses, however, the ability of metastasis is strong especially in the LUAD advanced stage (stage III/IV), and most patients have a terrible 5-years survival outcome (Blandin Knight et al. 2017). At present, the main treatment methods of LUAD include target therapies, combination therapies, immunotherapy, and surgery resection therapy (Denisenko, Budkevich and Zhivotovsky 2018). It is necessary to identify novel biomarkers correlated with progression of LUAD to serve as prognostic factors and therapeutic targets for LUAD. Recently, increasing mRNAs were reported as potential targets for LUAD and to comprehend LUAD genesis mechanism. For instance, SNAI1 and SNAI2 exerted aggressive properties of LUAD (Ge et al. 2019). SIRT6 functioned as an oncogene in LUAD.

Enhanced expression of TEK in 14 lung adenocarcinoma samples and paired adjacent noncancerous lung tissues was first detected in 1999 (Takahama et al. 1999). In the next year, it was found significantly down-regulated during in non-small cell lung carcinoma (Wong et al. 2000). Then, the significant relation between TEK and vascularization was further elaborated in non-small cell lung carcinoma (Hatanaka et al. 2001, Shepherd 2001, Favre et al. 2003). The function of TEK has been extensively studied in pulmonary hypertension (Sullivan et al. 2003, Zhao et al. 2003, Du et al. 2003, Kido et al. 2005, Dewachter 
et al. 2006). Interestingly, some claimed that TEK could not be used as a chemotherapy responsive predictor (Naumnik, Chyczewska and Ossolinska 2009), whereas some claimed that TEK level might reflect the patients' response to chemotherapy (Mroz et al. 2013). It was not until 2018 when TEK was firstly identified as a core gene participating in angiogenesis, cell growth, cytokine secretion, and inflammatory response in LUAD (Tian et al. 2018). Then, in 2019, a subset of circulating monocytic myeloid-derived suppressor cells overexpressing ANGPT2 and TEK was identified as a participant in tumor immune evasion that could enlighten future immunotherapy approaches for non-small cell lung carcinoma (Lauret Marie Joseph et al. 2019). However, lung adenocarcinoma-genesis mechanism involving TEK has not been studied.

MicroRNA (miRNA) is a short sequence with 22 nucleotides, and often plays a main role in gene transcription to participate in many cellular functions including cell apoptosis, cell proliferation as well as cell cycle progression (Hammond 2015, Di Leva, Garofalo and Croce 2014, Li et al. 2018, Wang et al. 2017a). MiRNAs could interact with many key genes to promote or suppress the occurrence of cancer. For instance, miR-125b-1 inhibited the expression of TACSTD2 to suppress the progression of head and neck cancer (Nakanishi et al. 2014). MiR-146a targeted IRS2 to inhibit the cell growth in the esophageal squamous cell carcinomas (Liu et al. 2016). Contrarily, miR-31-5p was reported as an oncogene that enhanced the cell proliferation of oral cancer (Lu et al. 2019). Since 2013, nearly 40 articles have reported the different roles that miR-19a-3p plays in various types of tumors, such as a suppressor in breast cancer (Yang et al. 2014), and an oncogene in gastric cancer (Li et al. 2019) etc. Low level of miR-19a-3p in non-small cell lung cancer was also reported (Fan et al. 2018). For the first time, we explored the involvement of the interaction between miR-19a-3p and its downstream effector TEK in regulating the cancerous phenotypes of lung adenocarcinoma cells.

In the study, we aimed to investigate the effects of TEK and the interacting miRNA, miR-19a-3p, in LUAD. Our study revealed a novel interactome of miR-19a-3p and TEK that modified the malignancy phenotypes of LUAD cell.

\section{Methods}

\section{Tissue samples}

Lung adenocarcinoma tissues and normal lung tissues in our research were collected from 20 patients in the Edong Healthcare Group, Huangshi Central Hospital (Affiliated Hospital of Hubei Polytechnic University). The hospital Ethics Committee approved our study. The baseline characteristics of these patients were shown in Table 1. 
Table 1

The relationship between TEK expression and clinicopathologic features from patients with lung cancer ( $\mathrm{n}$ $=20)$.

\begin{tabular}{|llll|}
\hline & Number & TEK low & $P$ value \\
\hline Age (years) & & & 0.892 \\
\hline$\geq 45$ & 8 & 9 & \\
\hline 45 & 12 & 11 & \\
\hline Tumor size $(\mathrm{cm})$ & & & 0.042 \\
$\geq 3$ & 7 & 6 & \\
\hline \3 & 13 & 14 & \\
\hline TNM stage & & & 0.691 \\
\hline I-II & 11 & 7 & \\
\hline III-IV & 9 & 13 & \\
\hline Lymph node metastasis & & & \\
\hline No & 13 & 5 & 0.039 \\
\hline Yes & 6 & 15 & \\
\hline
\end{tabular}

\section{Cell Culture And Transfection}

The normal lung cell line BEAS-2B and lung adenocarcinoma cell lines A549, Calu-3, and H1975 were obtained from Chinese Academy of Sciences cell bank (Shanghai, China). DMEM (Gibco BRL, Grand Island, NY, USA) supplemented with 10\% FBS (Gibco, Carlsbad, CA) was applied for cell culture, and the cell culture atmosphere was $37{ }^{\circ} \mathrm{C}$ and $5 \% \mathrm{CO}_{2}$. The TEK overexpression (OE) plasmids,miR-19a-3p mimic and miR-19a-3p inhibitor were obtained from GeneChem (Shanghai, China). The Lipofectamine 3000 reagent (Invitrogen, Carlsbad, CA, USA) was employed for transfection.

\section{Quantitative Real-time Pcr}

Total RNA extracted by TRIzol (Invitrogen, CA, USA) was applied for reverse transcription and cDNA amplification using SYBR Green PCR kit on an ABI 7300 system (Applied Biosystems, USA). The $2^{-\triangle \triangle C t}$ method was employed to calculate the relative expression. The primer sequences for TEK, miR-19a-3p and the corresponding internal reference genes were provided in Table 2. 
Table 2

The sequences of the primers in this study

\begin{tabular}{|ll|}
\hline Primer/Antibody & Sequences/Antibody information \\
\hline miR-19a-3p & \\
\hline Forward sequence & 5'-GTCCTCTGTTAGTTTTGCATAGTTG-3' \\
\hline Reverse sequence & 5'-GGCCACCATCAGTTTTGCATAG-3' $^{\prime}$ \\
\hline TEK & \\
\hline Forward sequence & 5'-CCTTGGCTCTGCTGGAATGA-3' \\
\hline Reverse sequence & 5'-CACGTTTTGGAAGGCTTGGG-3' \\
\hline GAPDH & \\
\hline Forward sequence & 5'-GTCAAGGCTGAGAACGGGAA-3' \\
\hline Reverse sequence & 5'-AAATGAGCCCCAGCCTTCTC-3' \\
\hline U6 & \\
\hline Forward sequence & 5'-TGCGGGTGCTCGCTTCGGCAGC-3' \\
\hline Reverse sequence & 5'-CCAGTGCAGGGTCCGAGGT-3' \\
\hline TEK & Cat\#: ab24859, Abcam, USA \\
\hline GAPDH & Cat\#: ab9485, Abcam, USA \\
\hline
\end{tabular}

\section{Western Blot Assay}

A549 and H1975 cells were harvested to extract proteins by lysis buffer (Thermo Scientific, Rockford, IL, USA). After measuring the concentration, proteins were firstly separated by electrophoresis, then transferred to PVDF membrane, and incubated with primary and secondary anti-bodies. Eventually, the protein band was detected and analyzed by BCA kit (Pierce, USA) and Image J Software (Bio-Rad Laboratories, San Diego, CA, USA). The anti-bodies were shown in Table 2.

\section{3'utr Reporter Assay}

The reporter plasmids contained PsiCHECK2-TEK-Mut1 (3'UTR 827-833), PsiCHECK2-TEK-Mut2 (3'UTR 892-898) and psiCHECK2-TEK-Wt, which were constructed with the psiCHECK2 plasmids (Promega, Madison, WI, USA). A549 and H1975 cells that were transfected with miR-19a-3p mimic or miR-NC were plated in 96-well plates for $48 \mathrm{~h}$ of incubation. Then luciferase activities were quantified using a luminometer. 


\section{Cell Proliferation And Cell Apoptosis Assay}

CCK-8 and EDU fluorescence proliferation assay were used to determine cell proliferation. The CCK-8 kit (Sigma Aldrich Company Ltd, Poole, Dorset, UK) was firstly applied to determine the cell proliferation of A549 and H1975 cells according to the protocol. After incubation for $0,24,48$, and 72 hours, each well was added with CCK-8 reagents to keep incubating for one hour. The optical absorbance of live A549 and $\mathrm{H} 1975$ cells at $450 \mathrm{~nm}$ was demonstrated by an automatic microplate reader (Bio-Rad, Hercules, CA, USA). For EDU fluorescence proliferation assay, $2 \times 10^{4}$ cells/well were firstly plated in 48-well plates. 100 $\mu \mathrm{L}$ of EDU solution ( $10 \mu \mathrm{M}$, Abcam, USA, \#ab219801) was incubated with cells for $4 \mathrm{~h}$ at $37^{\circ} \mathrm{C}$. After washing with PBS three times, the cells were fixed with 4\% paraformaldehyde in PBS for 15 min and permeabilized by the addition of $200 \mu \mathrm{l}$ permeabilization buffer for $20 \mathrm{~min}$. Thereafter, $100 \mu \mathrm{L}$ of iFluor 488 staining solution was added to each well and incubated for 30 min in the dark at room temperature. After the solution was removed, $100 \mu \mathrm{L}$ of DAPI $(5 \mu \mathrm{g} / \mathrm{mL})$ nuclear staining solution was added to each well and incubated for $10 \mathrm{~min}$. Finally, the cells were visualized under a fluorescence microscope. The ratio of EDU-positive cells (green) to all DAPI-positive cells (blue) represents the proliferation ratio. The cell apoptosis rate of A549 and H1975 cells was measured by flow cytometry (BD Biosciences, San Jose, $\mathrm{CA}$, USA). The cells in the well were stained with Annexin V/propidium iodide ( $\mathrm{PI}$ ) reagents (KeyGen Biotech). The sum of upper-right quadrant (Annexin $\mathrm{V}+/ \mathrm{PI}+$ ) and lower-right quadrant (Annexin $\mathrm{V}+/ \mathrm{PI}-$ ) represented the cell apoptosis rate.

\section{Cell Migration And Adhesion Assays}

For wound healing assay to detect cell migration, scratches on cell culture surfaces were made using plastic pipette tips. The cells were cultured without FBS for 48 hours, and the migrated lengths symbolized the cell migration ability. Cell adhesion mechanism is complex. It is involved in a variety of aggressive processes including cell migration and invasion and potential cell-cell communication. To determine the cell adhesion to extracellular matrix, a colorimetric method was employed. Briefly, 96-well plates were coated with collagen type I ( $50 \mathrm{lg} / \mathrm{ml}$; Sigma Chemical Co., Steinheim, Germany) at $4{ }^{\circ} \mathrm{C}$ overnight. A549 and $\mathrm{H} 1975$ cells were allowed to adhere at $37^{\circ} \mathrm{C}$. Cell culture was washed with DMEM for three times. At 30 min and 60 min, unbound A549 and H1975 cells were washed away, and adherent cells were fixed with $4 \%$ paraformaldehyde, and stained with crystal violet $(0.5 \%)$ for 10 minutes. After stain extraction, the relative cell attachment was determined using absorbance readings at $620 \mathrm{~nm}$.

\section{Statistical Analysis}

The GraphPad PRISM Version 8.0.1 statistical program (San Diego, CA, USA) was employed for our data (expressed as mean \pm standard deviation) analysis, and diagram construction. Statistical significance was determined by one-way ANOVA followed by Dunnett's post hoc tests for multiple-group data, and Student's t test for two independent-group data. Probability smaller than 0.05 was regarded statistically significant. Each experiment was performed at least three times independently. 


\section{Results}

\section{Microarray analysis of potentially core participants of LUAD}

GSE118370 (Normal: $n=6$; Tumor: $n=6$ ) and GSE89039 (Normal: $n=8$; Tumor: $n=8$ ) went through GEO2R analyses. A Venn diagram was drawn to identify the 540 overlapping differentially expressed genes (DEGs) of GSE118370 and GSE89039 (Fig. 1A). These 540 DEGs then underwent functional enrichments using STRING (Fig. 1B) and Metascape (Fig. 1C) algorithms. STRING algorithm showed that these DEGs were significantly related to regulation of migration (Fig. 1B), whereas Metascape algorithm showed that the DEGs were significantly related to regulation of adhesion (Fig. 1C). The built-in MCODE algorithm of Metascape identified the core genes (Fig. 1D). Cell migration and adhesion phenotypes were significant cancerous cell phenotypes, thus were chosen for further key genes identification. 31 genes were identified to participate in both cell migration and adhesion of lung adenocarcinoma (Fig. 1E). WEBGESTALT software was finally used to enrich KEGG terms of the 31 DEGs. And they were shown to be significantly related to PI3K-Akt signaling pathway. To be specific, ANGPT1, LAMA2, LAMA3, LAMA4, ITGA6, PIK3R1 and TEK were enriched to be participants of PI3K-Akt signaling (Fig. 1F). Among them, ANGPT1, LAMA3, ITGA6 and TEK were also identified by the MCODE algorithm in the last step. Then ENCORI algorithm (Li et al. 2014) was employed to analyse the relationship between the expression of the 7 genes and the overall survival outcomes of LUAD patients. The results showed that LUAD patients with lower level of IPK3R1 and TEK displayed significantly poorer survival outcomes compared to patients with high expression of PIK3R1 and TEK. And the other five DEGs did not relate to the survival of LUAD patients. Interestingly, a high level of ITGA6 seemed to predict a significantly better survival outcome (Fig. 2A-G).

\section{The low expression of TEK in lung adenocarcinoma tissues and cell lines}

GEPIA was used to preliminarily analyse the expression of ITGA6, PIK3R1 and TEK. ITGA6 was shown to be significantly upregulated in LUSC but not in LUAD, in which type of cancer it was not found significantly differentially expressed in tumor tissues and healthy tissues (Fig. 3A). PIK3R1 and TEK, on the other hand, were both shown to be significantly downregulated in both LUSC and LUAD. In particular, TEK (Fig. 3B-C). Fig. 3D gives an overall insight into the expression levels of the three genes in LUAD and LUSC. We further verified the mRNA expression of TEK and PIK3R1 in LUAD tissues and healthy tissues that we collected. Both TEK and PIK3R1 exhibited an approximately half level in tumor tissues of normal tissues (Fig 3E-F). Similarly, the expression of TEK and PIK3R1 mRNA (Fig. 3G) and protein (Fig. 3I) in LUAD cell lines was obviously lower than in normal lung cell line. Notably, compared to PIK3R1, TEK was more significantly downregulated in LUAD tissue samples and cell lines than in healthy tissues and cell line. Thus, TEK was chosen for further experiments. Then, we found that A549 and H1975 cell lines demonstrated the most significantly down-regulation of TEK, thus were chosen as the cell lines for further experiments.

\section{TEK suppressed the progression of LUAD in vitro}


Before the cellular experiments, the transfection efficiency of TEK overexpression plasmids was confirmed in both A549 and H1975 cell lines (Fig 4A-B). CCK-8 and EDU assay were performed to study the suppressive effect of TEK on LUAD cell proliferation. Compared with the blank control group, TEK overexpression significantly suppressed A549 cell line proliferation at $48 \mathrm{~h}$ and $72 \mathrm{~h}$ (Fig 4C), and H1975 cell line at $72 \mathrm{~h}$ (Fig 4D). Then, EDU assay results confirmed the CCK-8 results (Fig 4E-F). On the other hand, the overexpression of TEK distinctly increased the cell apoptosis rate in A549 (Fig 4G) and H1975 (Fig $4 \mathrm{H}$ ) cells. Scratch assay results showed that exogenous TEK overexpression led to significant impairment of migration of LUAD cells. The migration rate of A549 cells was reduced by over $50 \%$, and that of $\mathrm{H} 1975$ cells was reduced by more than 40\% (Fig 5A-B). In addition, the results of cell adhesion assay showed that TEK overexpression had no effect on the adhesion ability of LUAD cells at $30 \mathrm{~min}$, but at $60 \mathrm{~min}$, the adhesion ability of LUAD cells was obviously weaker (approximately 1/3 weaker in A549 cells and 1/2 in H1975 cells) (Fig 5C-D).

\section{MiR-19a-3p directly targeted TEK in LUAD}

miRDB and TargetScan Human 7.2 algorithms were used to predict potential upstream miRNAs for TEK. 71 common candidates were identified (Fig. 6A). dbDEMC database was used to do a meta profiling of the 71 miRNAs in lung cancer. 12 candidates were found significantly (Fig. 6B), whilst the others were found significantly downregulated upregulated in lung cancer (data not shown). miRDB predicted that miR-19a-3p might target sequences 827-833 and 892-898 on the 3'UTR of TEK (Fig 6C). The 3'UTR reporter assay results confirmed that. The relative luciferase activity of the cells with wild-type 3'UTR sequences (827-833 and 892-898), particularly 827-833 region, and miRNA mimic was significantly lower (Fig 6D). The high level of miR-19a-3p was determined in both LUAD tissues (Fig 6E) and LUAD cell lines (Fig 6F). As expected, correlation analysis indicated an inverse correlation relationship between miR-19a$3 p$ and TEK mRNA expression (Fig 6G). In addition, the transfection efficiency of miR-19a-3p inhibitor and miR-19a-3p mimic in A549 and H1975 cells were analyzed by qRT-PCR. The efficiency of inhibitor reached approximately $75 \%$ (Fig 6H).

\section{miR-19a-3p promoted LUAD cancerous phenotypes}

Whether miR-19a-3p could regulate LUAD cell phenotypes was also answered by our experiments. In both A549 and H1975 cell lines, miR-19a-3p mimic significantly facilitated cell proliferation, while miR-19a-3p inhibitor impaired it at $48 \mathrm{~h}$ and $72 \mathrm{~h}$ (Fig 7A). Another hall marker of malignancy, migration ability, was enhanced by approximately $2 / 3$ by miR-19a-3p upregulation and suppressed by miR-19a-3p inhibition (by approximately 1/3) in A549 cells. Similarly, miR-19a-3p upregulation led to approximately $1 / 4$ increase of migration whereas the inhibitor led to approximately $1 / 3$ decrease of migration (Fig.7B). The adhesion ability of A549 and H1975 cells to extracellular matrix was obviously enhanced by miR-19a-3p upregulation (by approximately 25\% in A549 cells and H1975 cells) and impaired by miR-19a-3p suppression at 60 min (by approximately 30\% in A549 cells and 20\% H1975 cells) (Fig. 7C).

\section{MiR-19a-3p negatively regulated TEK in LUAD}


Finally, rescue experiments were carried out to illuminate whether TEK was the potential downstream effector of miR-19a-3p in LUAD. TEK overexpression led to significantly impaired cell proliferation, which was reconstructed by miR-19a-3p mimic in A549 (at $48 \mathrm{~h}$ and $72 \mathrm{~h}$ ) and $\mathrm{H} 1975$ cells (at $72 \mathrm{~h}$ ) (Fig 8A). TEK overexpression obviously suppressed the ability of cell migration, which was abrogated by miR-19a3p mimic in A549 and H1975 cells (Fig 8B). As expected, miR-19a-3p mimic significantly restored the inhibition on cell adhesion ability induced by TEK upregulation in A549 and H1975 cells (Fig 8C).

\section{Discussion}

We have used $\mathrm{A} 549$ and $\mathrm{H} 1975$, two lung adenocarcinoma cell lines, to investigated into the potential therapy target, the miR-19a-3p/TEK axis. We found that TEK was significantly downregulated in LUAD tissues and cell lines, and hypothesized that TEK might be a LUAD suppressor. On the other hand, we identified a potential regulator of TEK, miR-19a-3p. How miR-19a-3p promoted LUAD phenotypes by targeting TEK was studied in our work.

Previous studies indicated that TEK might be promising prognosis markers in cancers such as clear cell renal carcinoma (Nakashima et al. 2019). TEK was reported to be associated with the complete response to bevacizumab in breast cancer patients (Makhoul et al. 2017). TEK also could modulate the interaction of glioma and brain tumor stem cells, and promote an invasive phenotype (Liu et al. 2010). Furthermore, TEK is a novel prognostic marker for clear cell renal cell carcinoma (Pan et al. 2019). However, how TEK affects the invasive cancerous phenotypes of LUAD remains largely unknown. We herein reported that TEK was significantly downregulated in LUAD tissues and cell lines compared with normal tissues and cell lines. The low level of TEK not only predicted a poorer survival outcome of LUAD patients, but also was related to tumor staging. The overexpression of TEK results in significant impaired proliferation and aggression abilities of LUAD cell lines, suggesting its possible LUAD suppressor role.

High serum miR-19a level could be an independent poor prognostic indicator for non-small cell lung cancer because it is significantly related to the malignancy characteristics of non-small cell lung cancer patients (Lin et al. 2013). miR-19a-3p has also been found to fulfil its regulation effects by targeting its downstream mRNAs in lung cancer. For instance, miR-19a-3p was reported to downregulate suppressor of cytokine signaling 1 (SCS1) to promote non-small cell lung cancer cell canceration (Wang and Chen 2015). miR-19a-3p has also constantly been reported to be related to chemotherapy resistance and epithelial mesenchymal transition (EMT). For instance, miR-19a-3p compelled gefitinib resistance and EMT of non-small cell lung cancer by targeting c-Met (Cao et al. 2017), sulforaphane resistance of lung cancer stem cells by targeting GSK3 $\beta$ (Zhu et al. 2017), and grape seed procyanidin extract resistance (Mao et al. 2016). Then, there were those researches reporting that miR-19a-3p promoted lung cancer by targeting MTUS1, a tumor suppressor (Gu et al. 2017), and MXD1 (Hu et al. 2016), for instance. In other human diseases, miR-19a-3p also showed impressive effects, e.g. miR-19a-3p inhibited autophagymediated cardiac fibrogenesis by targeting TGF- $\beta$ R II (Zou et al. 2016), and regulated osteosarcoma cells chemosensitivity by elevating the expression of PTEN, a tumor suppressor (Zhai et al. 2019). In addition, miR-19a-3p was reported to promote hepatocellular carcinoma metastasis and chemoresistance through 
the PTEN/Akt signaling (Qi et al. 2018). miR-19a-3p participated in so many biology processes, pathways and diseases (Wang, Li and Xue 2019, Bai et al. 2019, Chen et al. 2019). TEK was identified to participate in PI3K/Akt signaling in our bioinformatics analyses process; however, we did not study how TEK regulated PI3K/Akt signaling at this stage of our research. Then, again, to provide a solid basis for further studies on how miR-19a-3p regulates chemo-resistance, we thoroughly studied its effect on LUAD cell phenotypes. We herein reported that miR-19a-3p promoted LUAD cancerous phenotypes by targeting a novel downstream effector, TEK.

Certain limitations of the current research existed. On one hand, in vivo experiments should be conducted to confirm the in vitro results in the coming future. Then, epithelial-mesenchymal transition (EMT) is a hall marker of lung cancer-genesis. miR-19a-3p has been reported to induce EMT in A549 cell line and HCC827 cell line by targeting PTEN (Li et al. 2015). Whether miR-19a-3p could compel EMT by targeting TEK remains to be answered. In addition, the reported relationship of miR-19a-3p with chemotherapy resistance in lung cancer also calls for further study of how miR-19a-3p mediates drug resistance by targeting TEK. Finally, a thorough study into the effects of TEK and miR-19a-3p on PI3K-Akt signaling is warranted.

\section{Conclusions}

We for the first time reported a novel interactome, TEK/miR-19a-3p, in LUAD. This novel interactome existed and regulated cell phenotype changes in A549 cell line and H1975 cell line, both of which are LUAD cell lines. These results provided discreet evidences of the interaction between TEK and miR-19a-3p in LUAD cell lines. We thus concluded that TEK could possibly suppress the cancerous phenotypes of lung adenocarcinoma by interacting with miR-19a-3p.

\section{Abbreviations}

miRNAs microRNAs; PBS:phosphate bufered solution; EdU:5-ethynyl-2'-deoxyuridine; LUAD:Iung adenocarcinoma; qPCR:quantitative real-time PCR.

\section{Declarations}

\section{Acknowledgements}

Not applicable.

\section{Funding}

This research has received no funds.

\section{Availability of data and materials}


The datasets used during the current study are available from the corresponding author on reasonable request.

\section{Authors' contributions}

LW and NH designed the experiments. YCX and LD conducted the experiments. LLY collected the data. BTZ wrote the manuscript.

\section{Ethics approval and consent to participate}

Ethic Committee of the Second Hospital of Jilin University (Jilin, China) approved the study. Written informed consent was obtained from all patients.

\section{Consent for publication}

Not applicable.

\section{Competing interests}

There is no conflict of interest existed among the authors.

\section{References}

1. Bai R, Cui Z, Ma Y, Wu Y, Wang N, Huang L, Yao Q, Sun J. The NF-kappaB-modulated miR-19a-3p enhances malignancy of human ovarian cancer cells through inhibition of IGFBP-3 expression. Mol Carcinog. 2019;58:2254-65.

2. Blandin Knight S, Crosbie PA, Balata H, Chudziak J, Hussell T, Dive C. (2017) Progress and prospects of early detection in lung cancer. Open Biol, 7.

3. Cao X, Lai S, Hu F, Li G, Wang G, Luo X, Fu X, Hu J. miR-19a contributes to gefitinib resistance and epithelial mesenchymal transition in non-small cell lung cancer cells by targeting c-Met. Sci Rep. 2017;7:2939.

4. Chen Y, Wang W, Chen Y, Tang Q, Zhu W, Li D, Liao L. (2019) MicroRNA-19a-3p promotes rheumatoid arthritis fibroblast-like synoviocytes via targeting SOCS3. J Cell Biochem.

5. Daugaard I, Dominguez D, Kjeldsen TE, Kristensen LS, Hager H, Wojdacz TK, Hansen LL. Identification and validation of candidate epigenetic biomarkers in lung adenocarcinoma. Sci Rep. 2016;6:35807.

6. Denisenko TV, Budkevich IN, Zhivotovsky B. Cell death-based treatment of lung adenocarcinoma. Cell Death Dis. 2018;9:117.

7. Dewachter L, Adnot S, Fadel E, Humbert M, Maitre B, Barlier-Mur AM, Simonneau G, Hamon M, Naeije R, Eddahibi S. Angiopoietin/Tie2 pathway influences smooth muscle hyperplasia in idiopathic pulmonary hypertension. Am J Respir Crit Care Med. 2006;174:1025-33.

8. Di Leva G, Garofalo M, Croce CM. MicroRNAs in cancer. Annu Rev Pathol. 2014;9:287-314. 
9. Du L, Sullivan CC, Chu D, Cho AJ, Kido M, Wolf PL, Yuan JX, Deutsch R, Jamieson SW, Thistlethwaite PA. Signaling molecules in nonfamilial pulmonary hypertension. N Engl J Med. 2003;348:500-9.

10. Fan L, Sha J, Teng J, Li D, Wang C, Xia Q, Chen H, Su B, Qi H. Evaluation of Serum Paired MicroRNA Ratios for Differential Diagnosis of Non-Small Cell Lung Cancer and Benign Pulmonary Diseases. Mol Diagn Ther. 2018;22:493-502.

11. Favre CJ, Mancuso M, Maas K, McLean JW, Baluk P, McDonald DM. Expression of genes involved in vascular development and angiogenesis in endothelial cells of adult lung. Am J Physiol Heart Circ Physiol. 2003;285:H1917-38.

12. Ge X, Li GY, Jiang L, Jia L, Zhang Z, Li X, Wang R, Zhou M, Zhou Y, Zeng Z, Xiang J, Li Z. Long noncoding RNA CAR10 promotes lung adenocarcinoma metastasis via miR-203/30/SNAl axis. Oncogene. 2019;38:3061-76.

13. Gu Y, Liu S, Zhang X, Chen G, Liang H, Yu M, Liao Z, Zhou Y, Zhang CY, Wang T, Wang C, Zhang J, Chen X. Oncogenic miR-19a and miR-19b co-regulate tumor suppressor MTUS1 to promote cell proliferation and migration in lung cancer. Protein Cell. 2017;8:455-66.

14. Hammond SM. An overview of microRNAs. Adv Drug Deliv Rev. 2015;87,:3-14.

15. Hatanaka H, Abe Y, Naruke M, Tokunaga T, Oshika Y, Kawakami T, Osada H, Nagata J, Kamochi J, Tsuchida T, Kijima H, Yamazaki H, Inoue H, Ueyama Y, Nakamura M. Significant correlation between interleukin 10 expression and vascularization through angiopoietin/TIE2 networks in non-small cell lung cancer. Clin Cancer Res. 2001;7:1287-92.

16. Hu W, Jin P, Ding C, Liu W. miR-19a/b modulates lung cancer cells metastasis through suppression of MXD1 expression. Oncol Lett. 2016;12:1901-5.

17. Kido M, Du L, Sullivan CC, Deutsch R, Jamieson SW, Thistlethwaite PA. Gene transfer of a TIE2 receptor antagonist prevents pulmonary hypertension in rodents. J Thorac Cardiovasc Surg. $2005 ; 129: 268-76$.

18. Lauret Marie Joseph E, Laheurte C, Jary M, Boullerot L, Asgarov K, Gravelin E, Bouard A, Rangan L, Dosset M, Borg C, Adotevi O. (2019) Immunoregulation and Clinical Implications of ANGPT2/TIE2 + M-MDSC Signature in Non-Small Cell Lung Cancer. Cancer Immunol Res.

19. Li J, Yang S, Yan W, Yang J, Qin YJ, Lin XL, Xie RY, Wang SC, Jin W, Gao F, Shi JW, Zhao WT, Jia JS, Shen HF, Ke JR, Liu B, Zhao YQ, Huang WH, Yao KT, Li DJ, Xiao D. MicroRNA-19 triggers epithelialmesenchymal transition of lung cancer cells accompanied by growth inhibition. Lab Invest. 2015;95:1056-70.

20. Li JH, Liu S, Zhou H, Qu LH, Yang JH. starBase v2.0: decoding miRNA-ceRNA, miRNA-ncRNA and protein-RNA interaction networks from large-scale CLIP-Seq data. Nucleic Acids Res. 2014;42:D92-7.

21. Li L, Song Y, Shi X, Liu J, Xiong S, Chen W, Fu Q, Huang Z, Gu N, Zhang R. The landscape of miRNA editing in animals and its impact on miRNA biogenesis and targeting. Genome Res. 2018;28:132-43.

22. Li X, Yan X, Wang F, Yang Q, Luo X, Kong J, Ju S. Down-regulated IncRNA SLC25A5-AS1 facilitates cell growth and inhibits apoptosis via miR-19a-3p/PTEN/PI3K/AKT signalling pathway in gastric cancer. J Cell Mol Med. 2019;23:2920-32. 
23. Lin Q, Chen T, Lin Q, Lin G, Lin J, Chen G, Guo L. Serum miR-19a expression correlates with worse prognosis of patients with non-small cell lung cancer. J Surg Oncol. 2013;107:767-71.

24. Liu D, Martin V, Fueyo J, Lee OH, Xu J, Cortes-Santiago N, Alonso MM, Aldape K, Colman H. \& C. Gomez-Manzano (2010) Tie2/TEK modulates the interaction of glioma and brain tumor stem cells with endothelial cells and promotes an invasive phenotype. Oncotarget, 1, 700-9.

25. Liu H, Ren G, Zhu L, Liu X, He X. The upregulation of miRNA-146a inhibited biological behaviors of ESCC through inhibition of IRS2. Tumour Biol. 2016;37:4641-7.

26. Lu Z, He Q, Liang J, Li W, Su Q, Chen Z, Wan Q, Zhou X, Cao L, Sun J, Wu Y, Liu L, Wu X, Hou J, Lian K, Wang A. miR-31-5p Is a Potential Circulating Biomarker and Therapeutic Target for Oral Cancer. Mol Ther Nucleic Acids. 2019;16:471-80.

27. Makhoul I, Todorova VK, Siegel ER, Erickson SW, Dhakal I, Raj VR, Lee JY, Orloff MS, Griffin RJ, HenryTillman RS, Klimberg S, Hutchins LF, Kadlubar SA. Germline Genetic Variants in TEK, ANGPT1, ANGPT2, MMP9, FGF2 and VEGFA Are Associated with Pathologic Complete Response to Bevacizumab in Breast Cancer Patients. PLoS One. 2017;12:e0168550.

28. Mao JT, Xue B, Smoake J, Lu QY, Park H, Henning SM, Burns W, Bernabei A, Elashoff D, Serio KJ, Massie L. MicroRNA-19a/b mediates grape seed procyanidin extract-induced anti-neoplastic effects against lung cancer. J Nutr Biochem. 2016;34:118-25.

29. Mroz RM, Korniluk M, Panek B, Ossolinska M, Chyczewska E. sVEGF R1 and Tie-2 levels during chemotherapy of lung cancer patients. Adv Exp Med Biol. 2013;756:313-9.

30. Nakanishi H, Taccioli C, Palatini J, Fernandez-Cymering C, Cui R, Kim T, Volinia S, Croce CM. Loss of miR-125b-1 contributes to head and neck cancer development by dysregulating TACSTD2 and MAPK pathway. Oncogene. 2014;33:702-12.

31. Nakashima S, Jinnin M, Ide M, Kajihara I, Igata T, Harada M, Masuguchi S, Fukushima S, Masuzawa M, Masuzawa M, Amoh Y, Ihn H. A potential significance of circ_0024169 down regulation in angiosarcoma tissue. Intractable Rare Dis Res. 2019;8:129-33.

32. Naumnik W, Chyczewska E, Ossolinska M. Serum levels of angiopoietin-1, angiopoietin-2, and their receptor tie-2 in patients with nonsmall cell lung cancer during chemotherapy. Cancer Invest. 2009;27:741-6.

33. Pan Y, Xu T, Liu Y, Li W, Zhang W. Upregulated circular RNA circ_0025033 promotes papillary thyroid cancer cell proliferation and invasion via sponging miR-1231 and miR-1304. Biochem Biophys Res Commun. 2019;510:334-8.

34. Qi H, Sun Y, Jiang Y, Li X. (2018) Upregulation of circular RNA circ_0000502 predicts unfavorable prognosis in osteosarcoma and facilitates cell progression via sponging miR-1238. J Cell Biochem.

35. Shepherd FA. Angiogenesis inhibitors in the treatment of lung cancer. Lung Cancer. 2001;34(Suppl 3):81-9.

36. Siegel RL, Miller KD, Jemal A. Cancer statistics, 2015. CA Cancer J Clin. 2015;65:5-29.

37. Sullivan CC, Du L, Chu D, Cho AJ, Kido M, Wolf PL, Jamieson SW, Thistlethwaite PA. Induction of pulmonary hypertension by an angiopoietin 1/TIE2/serotonin pathway. Proc Natl Acad Sci U S A. 
2003;100:12331-6.

38. Takahama M, Tsutsumi M, Tsujiuchi T, Nezu K, Kushibe K, Taniguchi S, Kotake Y, Konishi Y. Enhanced expression of Tie2, its ligand angiopoietin-1, vascular endothelial growth factor, and CD31 in human non-small cell lung carcinomas. Clin Cancer Res. 1999;5:2506-10.

39. Tian W, Li YS, Zhang JH, Li JJ, Gao JH. Comprehensive Analysis of DNA Methylation and Gene Expression Datasets Identified MMP9 and TWIST1 as Important Pathogenic Genes of Lung Adenocarcinoma. DNA Cell Biol. 2018;37:336-46.

40. Wang K, Jin W, Song Y, Fei X. LncRNA RP11-436H11.5, functioning as a competitive endogenous RNA, upregulates BCL-W expression by sponging miR-335-5p and promotes proliferation and invasion in renal cell carcinoma. Mol Cancer. 2017a;16:166.

41. Wang LL, Chen ZS, Zhou WD, Shu J, Wang XH, Jin R, Zhuang LL, Hoda MA, Zhang H, Zhou GP. Downregulated GATA-1 up-regulates interferon regulatory factor 3 in lung adenocarcinoma. Sci Rep. $2017 b ; 7: 2551$.

42. Wang N, Li R, Xue M. Potential regulatory network in the PSG10P/miR-19a-3p/IL1RAP pathway is possibly involved in preeclampsia pathogenesis. J Cell Mol Med. 2019;23:852-64.

43. Wang X, Chen Z. MicroRNA-19a functions as an oncogenic microRNA in non-small cell lung cancer by targeting the suppressor of cytokine signaling 1 and mediating STAT3 activation. Int J Mol Med. 2015;35:839-46.

44. Wong MP, Chan SY, Fu KH, Leung SY, Cheung N, Yuen ST, Chung LP. The angiopoietins, tie2 and vascular endothelial growth factor are differentially expressed in the transformation of normal lung to non-small cell lung carcinomas. Lung Cancer. 2000;29:11-22.

45. Yang J, Zhang Z, Chen C, Liu Y, Si Q, Chuang TH, Li N, Gomez-Cabrero A, Reisfeld RA, Xiang R, Luo Y. MicroRNA-19a-3p inhibits breast cancer progression and metastasis by inducing macrophage polarization through downregulated expression of Fra-1 proto-oncogene. Oncogene. 2014;33:301423.

46. Zhai Z, Fu Q, Liu C, Zhang X, Jia P, Xia P, Liu P, Liao S, Qin T, Zhang H. Emerging Roles Of hsa-circ0046600 Targeting The miR-640/HIF-1alpha Signalling Pathway In The Progression Of HCC. Onco Targets Ther. 2019;12:9291-302.

47. Zhao YD, Campbell Al, Robb M, Ng D, Stewart DJ. Protective role of angiopoietin-1 in experimental pulmonary hypertension. Circ Res. 2003;92:984-91.

48. Zhu J, Wang S, Chen Y, Li X, Jiang Y, Yang X, Li Y, Wang X, Meng Y, Zhu M, Ma X, Huang C, Wu R, Xie C, Geng S, Wu J, Zhong C, Han H. miR-19 targeting of GSK3beta mediates sulforaphane suppression of lung cancer stem cells. J Nutr Biochem. 2017;44:80-91.

49. Zou M, Wang F, Gao R, Wu J, Ou Y, Chen X, Wang T, Zhou X, Zhu W, Li P, Qi LW, Jiang T, Wang W, Li C, Chen J, He Q, Chen Y. Autophagy inhibition of hsa-miR-19a-3p/19b-3p by targeting TGF-beta R II during TGF-beta1-induced fibrogenesis in human cardiac fibroblasts. Sci Rep. 2016;6:24747.

\section{Figures}




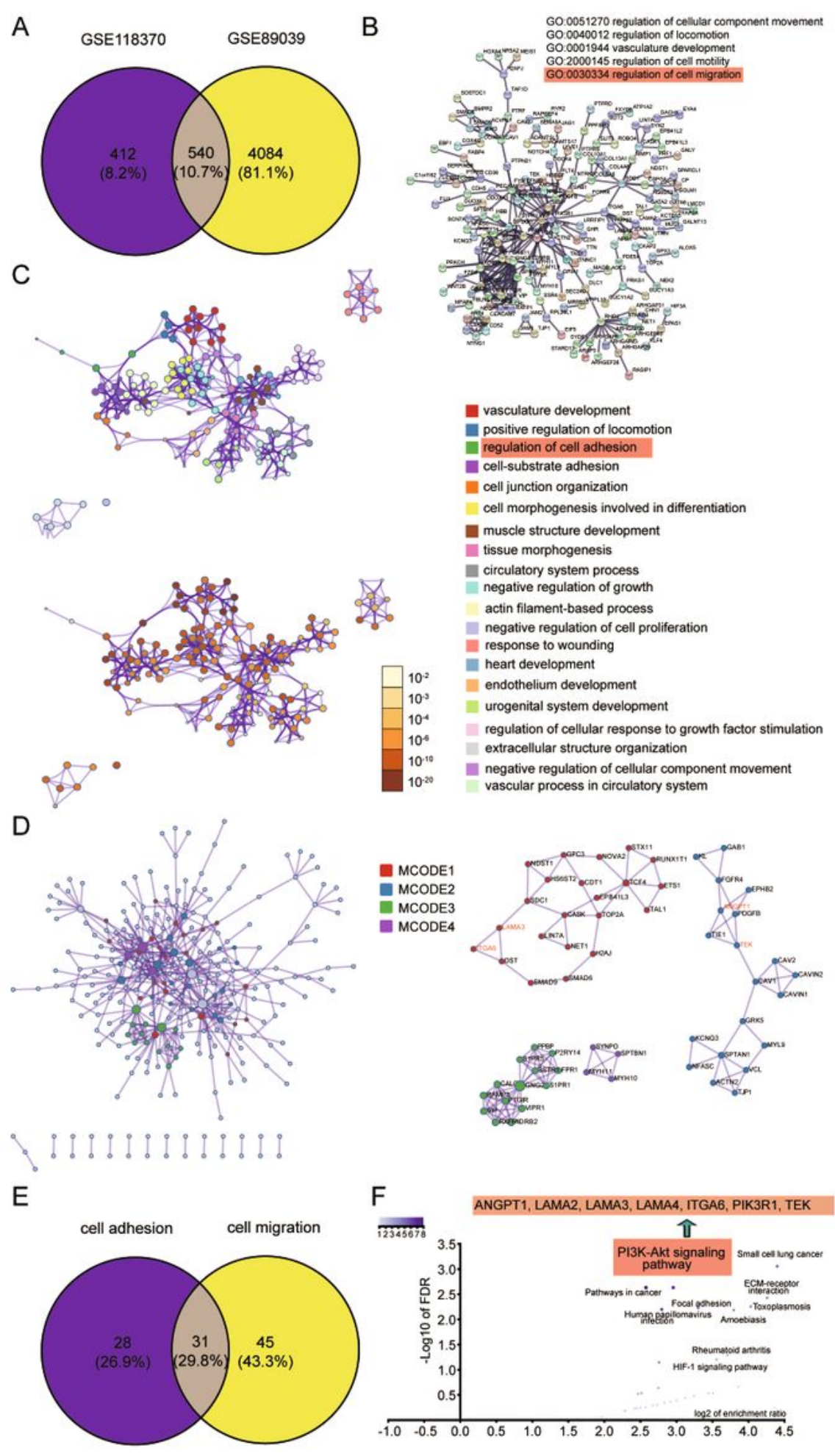

\section{Figure 1}

Identification of potential genes of interest that involve in lung adenocarcinoma. A. A Venn diagram demonstrating the 540 overlapped differentially expressed genes in GSE118370 and GSE89039 datasets. B. STRING analysis results of the overlapped 540 DEGs. C. Metascape results showing the enriched GO terms of the 540 DEGs. D. MCODE results showing the core networks and core genes that participate in the enriched functional processes. E. A Venn diagram showing the overlapped 31 genes that participate 
in both migration regulation pathway and the cell adhesion pathway. F. WEBGESTALT results showing the enriched KEGG pathways of the 31 genes.

A

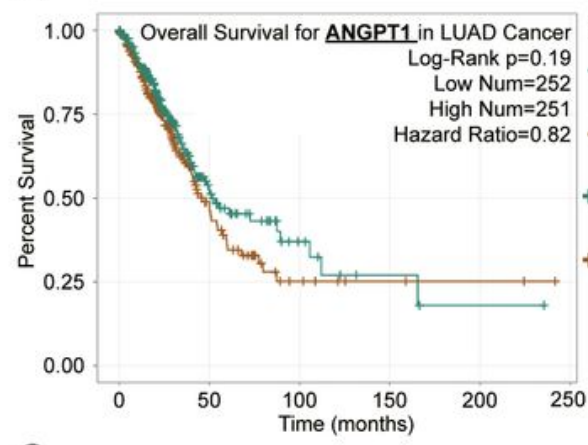

C

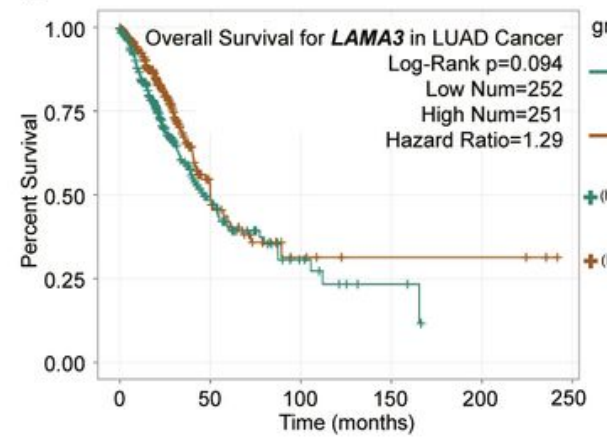

E

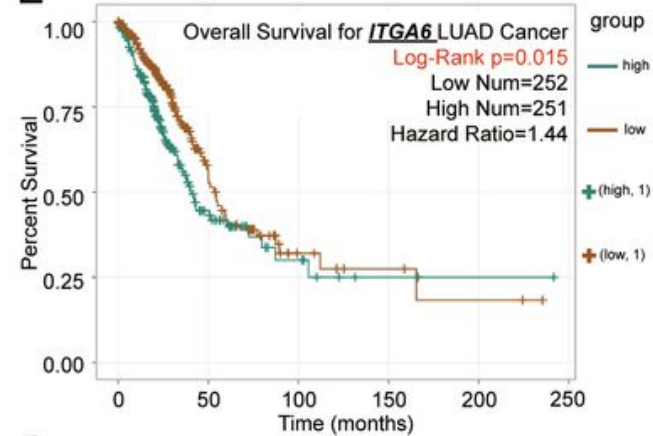

G

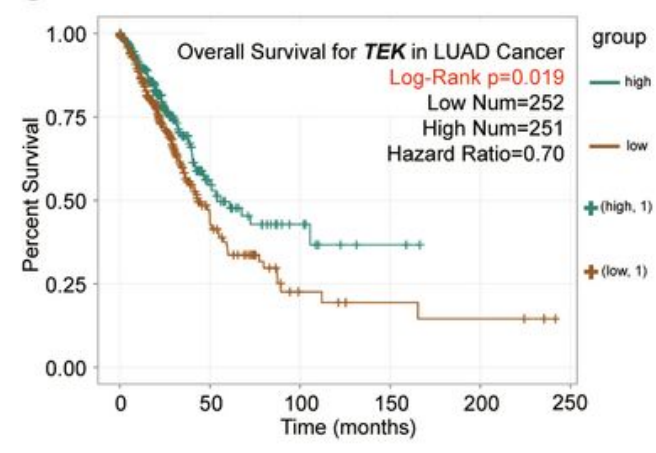

B

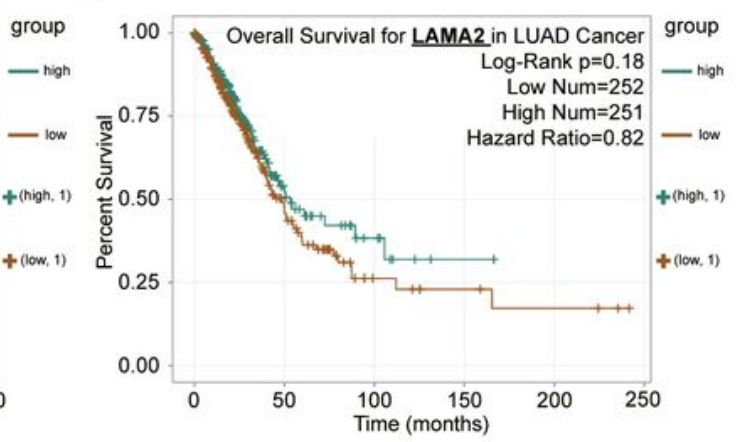

D

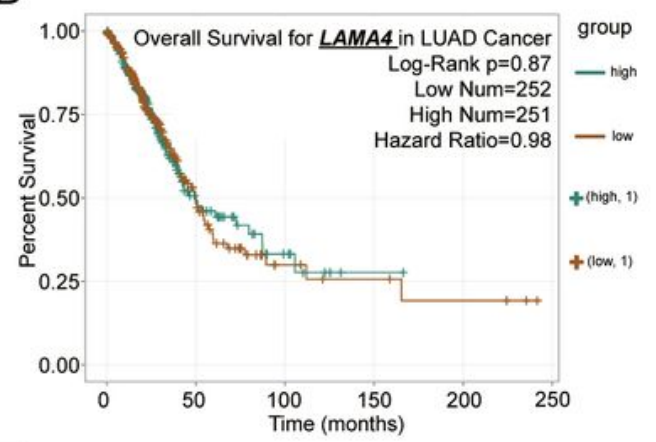

$\mathrm{F}$

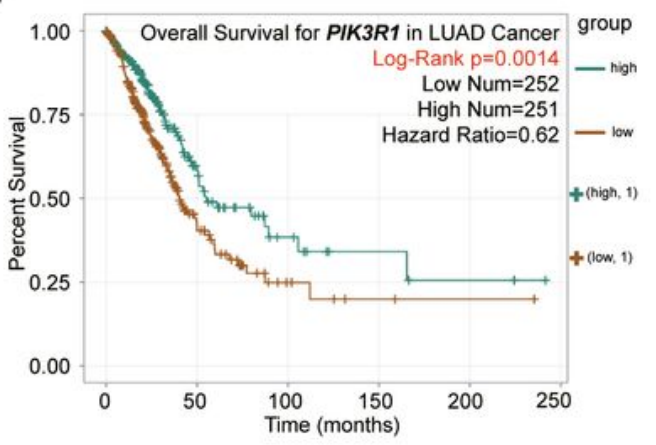

Figure 2

The overall survival analyses of the seven genes that participate in PI3K-Akt signaling. A-G represents the overall survival outcomes of LUAD patients with high and low levels of ANGPT1, LAMA2, LAMA3, LAMA4, ITGA6, PIK3R1 and TEK, respectively. 
A

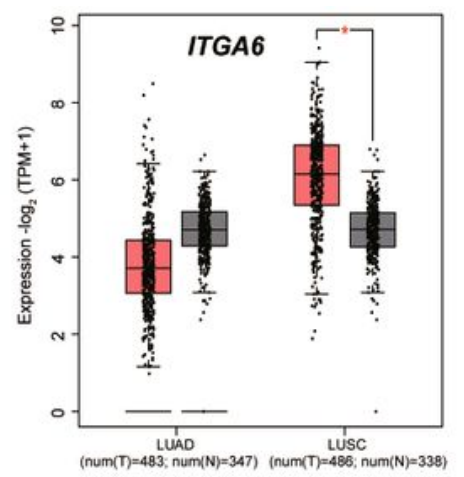

C

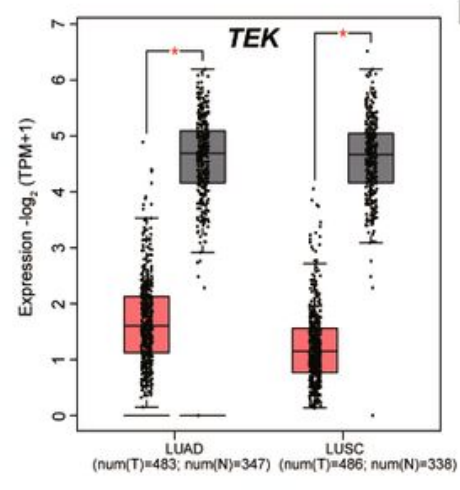

$\mathrm{E}$

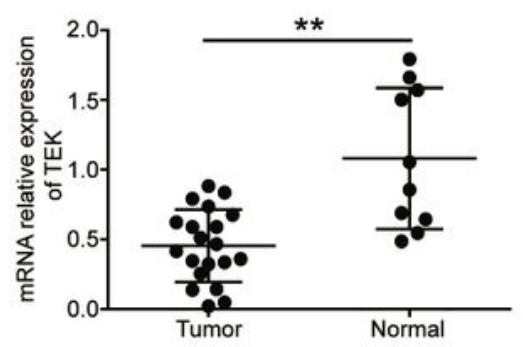

G

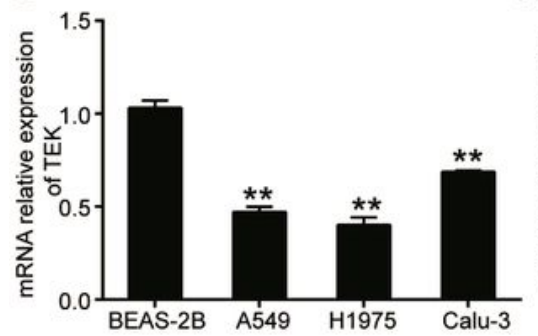

I
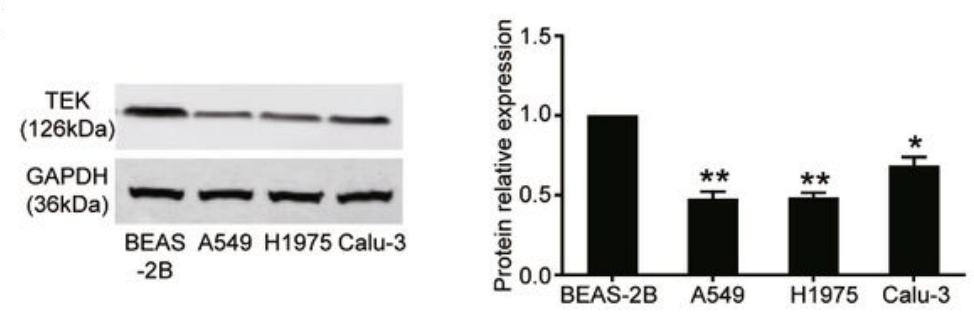

B

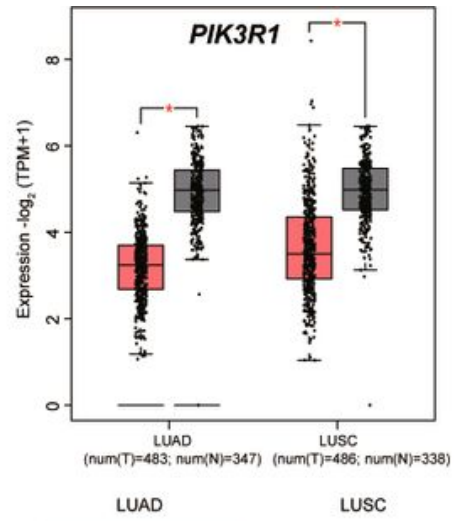

D
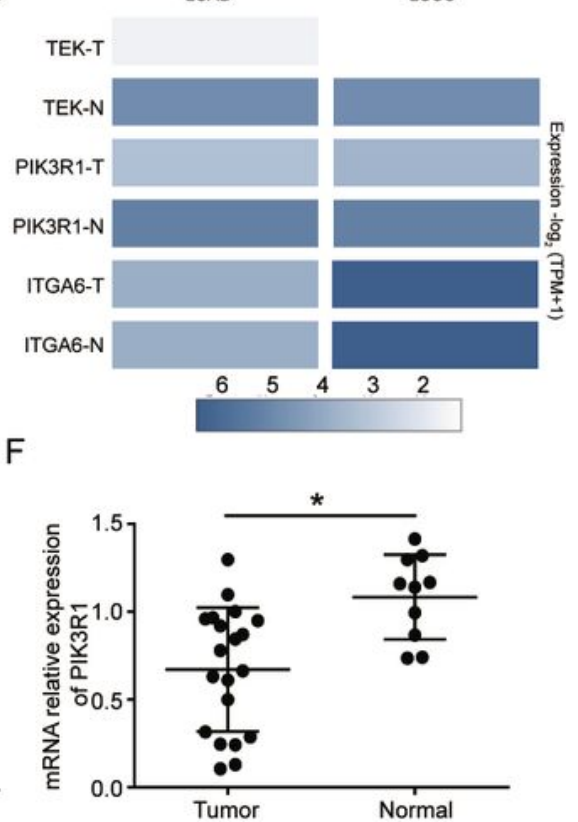

$\mathrm{H}$

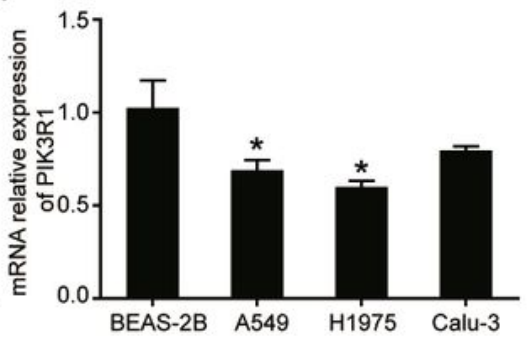

Figure 3

TEK mRNA is down-regulated in lung adenocarcinoma. A-C. GEPIA results for expression of ITGA6, TEK and PIK3R1 mRNA in LUAD (lung adenocarcinoma) and LUSC (lung squamous cell carcinoma). D. An overview of ITGA6, TEK and PIK3R1 expression in LUAD and LUSC tissues and healthy tissues. T: tumor; $\mathrm{N}$ : normal healthy tissues using GEPIA algorithm. E-F. TEK and PI3K1 mRNA expression in our collected LUAD tissues and normal healthy tissues. ${ }^{*} \mathrm{P}<0.05$, ${ }^{*} \mathrm{P}<0.01$, compared with normal tissues using $t$ test. 
G-H. TEK and PI3K1 mRNA expression in our selected cell lines. BEAS-2B cell line is immortalized normal control cell line, and the other three cell lines are LUAD cell lines. ${ }^{*} P<0.05,{ }^{*} \mathrm{P}<0.01$, compared with BEAS2B cell line using one-way ANOVA method. I. TEK protein expression in our selected cell lines. Only cropped blots were provided here. Uncropped blots were provided in additional files named Uncropped Blot of TEK expression in Figure $3 \mathrm{I}$ and Uncropped Blot of GAPDH expression in Figure $3 \mathrm{I}$. *P<0.05, **P $<0.01$, compared with BEAS-2B cell line using one-way ANOVA method.
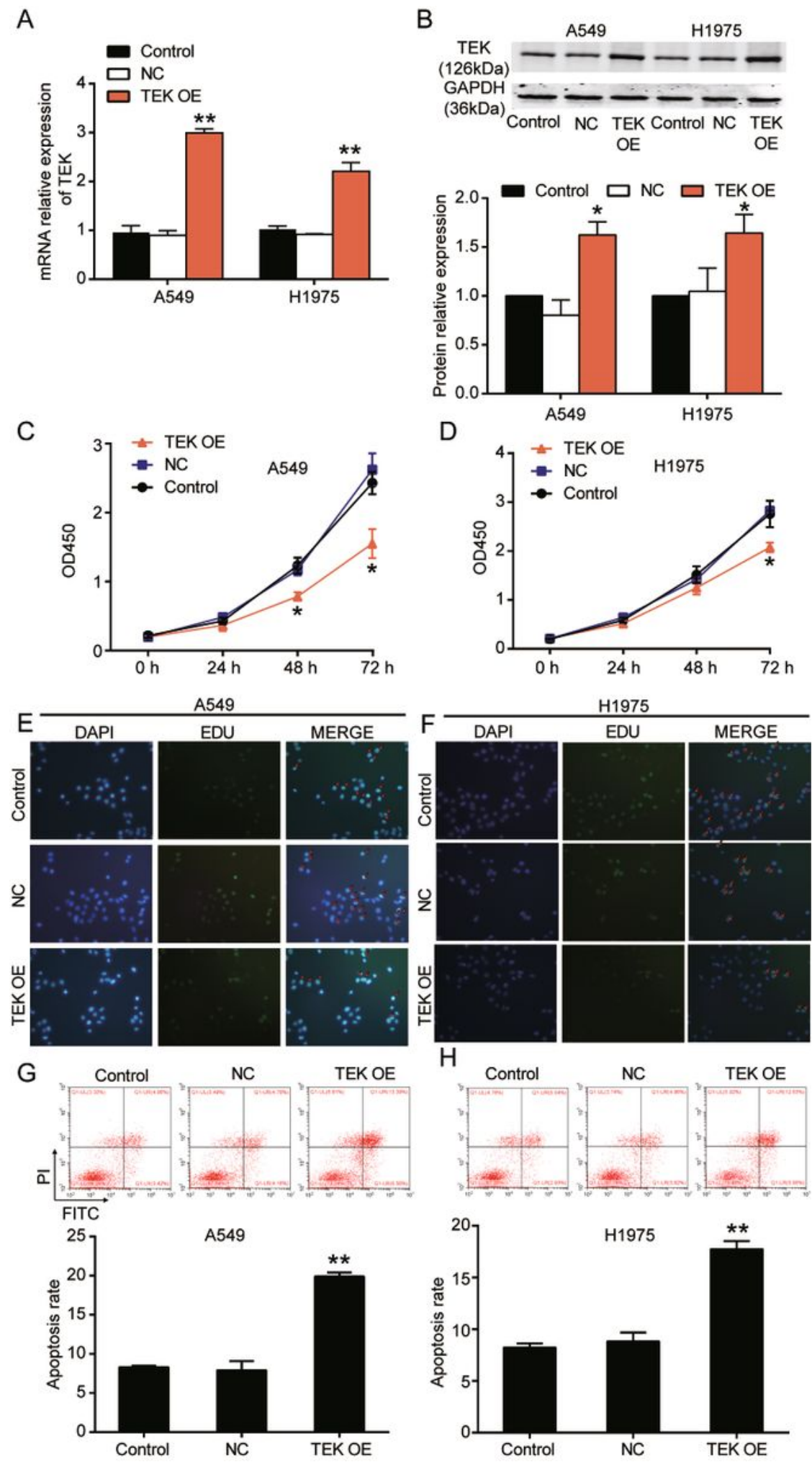

Figure 4 
TEK overexpression led to impaired A549 and H1975 cell proliferation and enhanced cell apoptosis. A-B. qPCR and immunoblot analyses showed the successful transfection of TEK overexpression plasmids in A549 and H1975 cell lines. TEK protein data are normalized to GAPDH protein levels. Only cropped blots were provided here. Uncropped blots were provided in additional files named Uncropped Blot of TEK expression in Figure 4B and Uncropped Blot of GAPDH expression in Figure 4B. C-D. CCK8 results of TEK overexpression in A549 and $\mathrm{H} 1975$ cell lines. E-F. EDU staining assay results of TEK overexpression in A549 and $\mathrm{H} 1975$ cell lines. The ratio of EDU-positive cells (green) to all DAPI-positive cells (blue) represents the proliferation ratio. The EDU-positive cells were also marked with red arrows in merged images. G-H. Flowcytometric apoptosis results of TEK overexpression in A549 and H1975 cell lines. The whole right quadrants were calculated into apoptosis. ${ }^{*}<<0.05,{ }^{\star} * \mathrm{P}<0.01$, compared with blank control group using one-way ANOVA method.
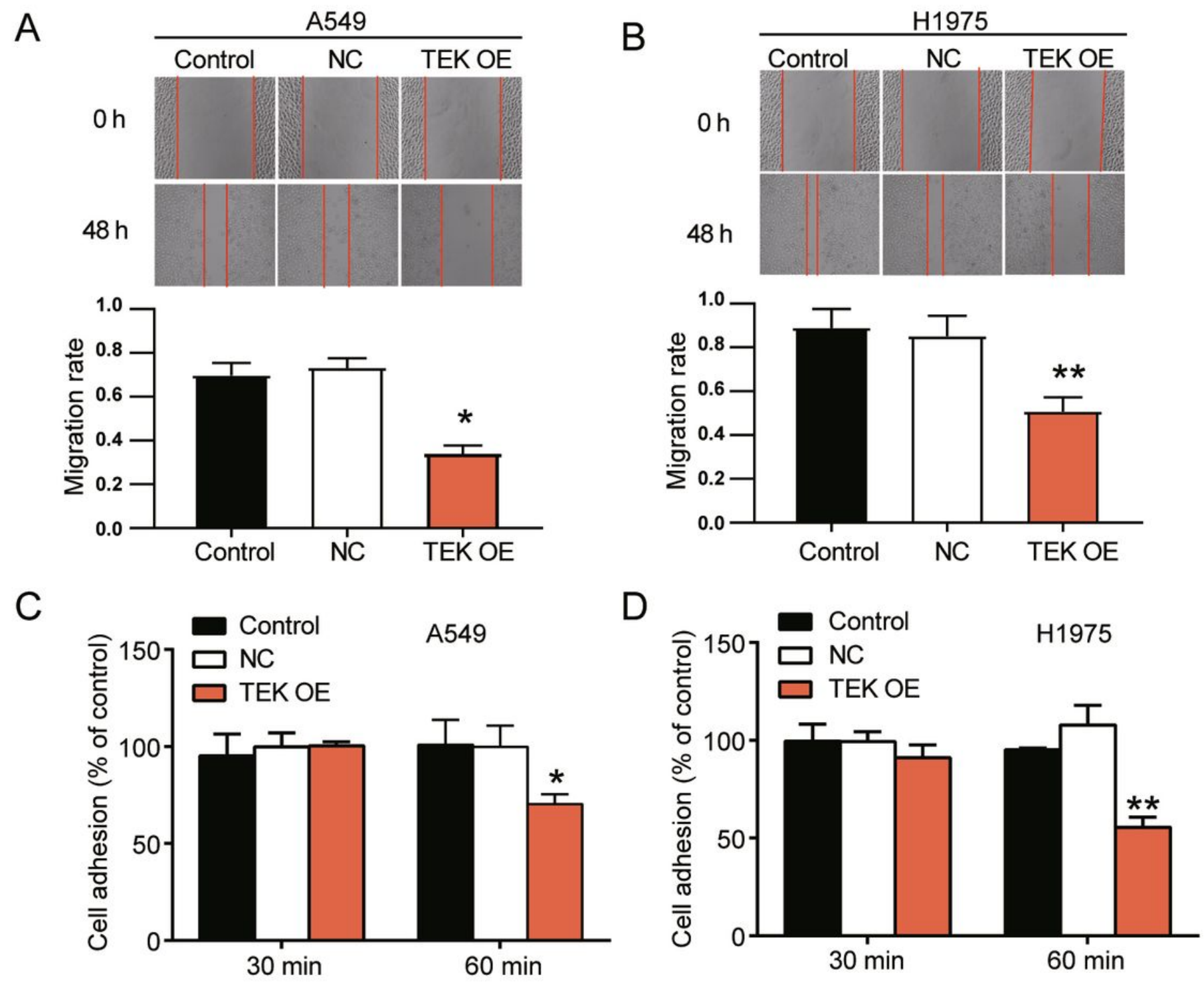

Figure 5 
TEK overexpression led to impaired A549 and H1975 cell migration and adhesion. A-B. Wound healing results of TEK overexpression in A549 and $\mathrm{H} 1975$ cell lines. C-D. Cell-extracellular matrix adhesion results of TEK overexpression in $A 549$ and $\mathrm{H} 1975$ cell lines. ${ }^{*} \mathrm{P}<0.05$, ${ }^{*} \mathrm{P}<0.01$, compared with blank control group using one-way ANOVA method.
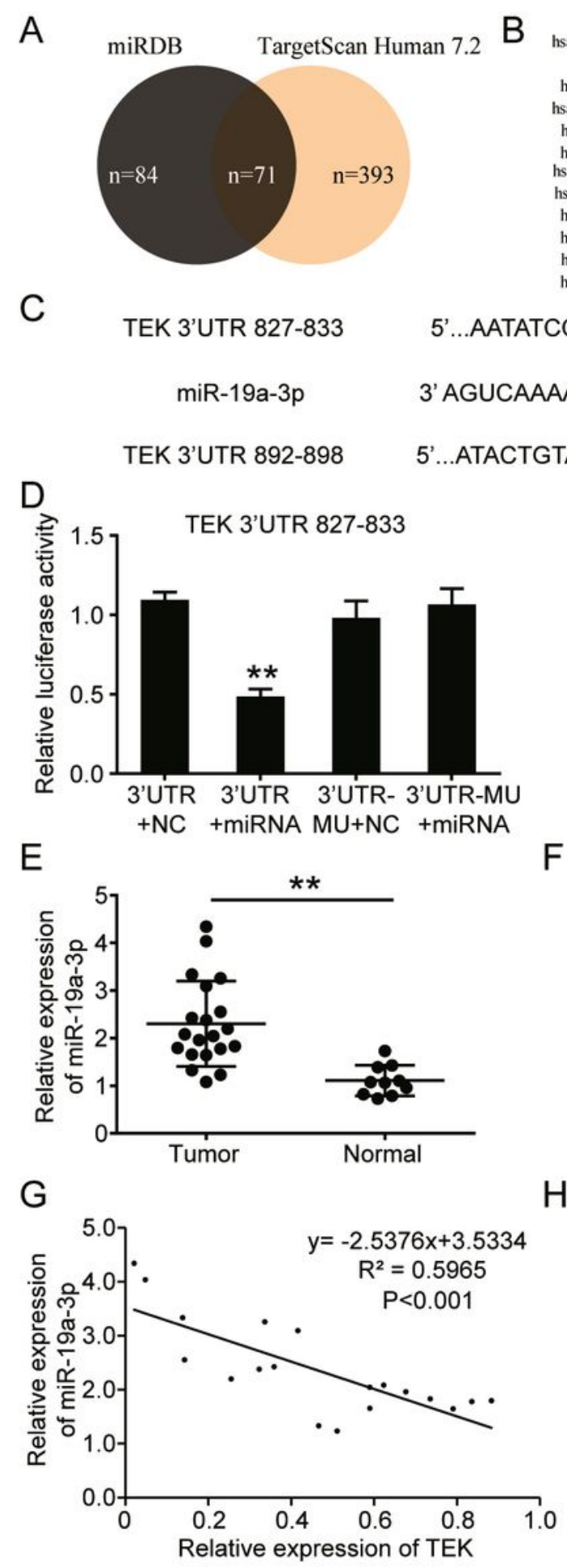

Meta profiling in lung cancer by dbDEMC 2.0

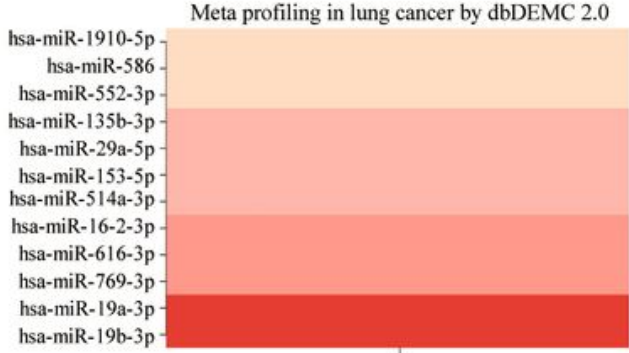

$\mathrm{F}$
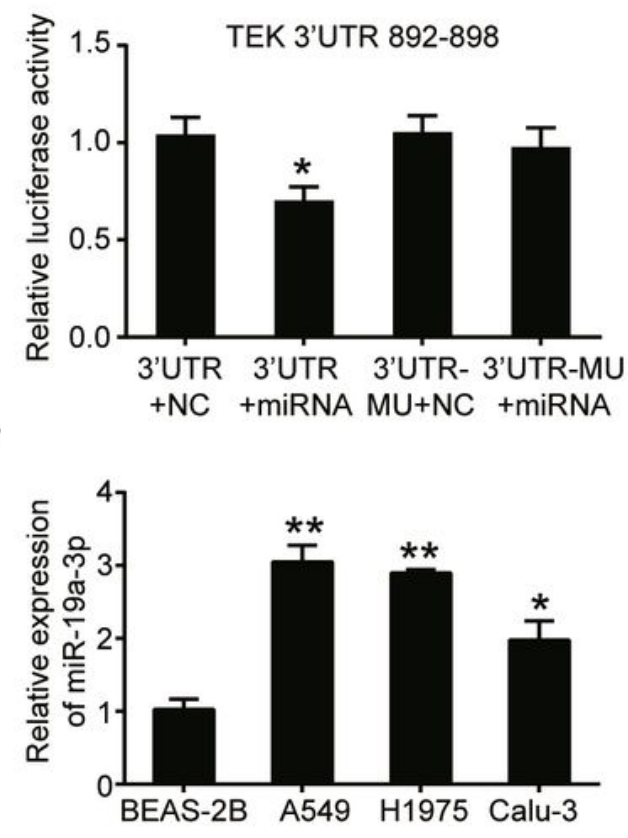

$\mathrm{H}$

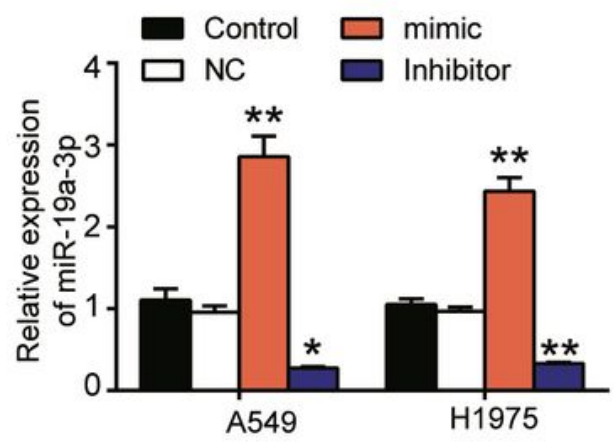

Figure 6 
miR-19a-3p is overexpressed in lung adenocarcinoma. A. 71 common upstream miRNAs that target TEK were identified using miRDB and TargetScan Human 7.2 algorithms. B. Meta profiling of the 71 miRNAs' expression levels in lung cancer. miR-19a/b-3p were shown to be the most significantly upregulated miRNAs. C. Schematic illustration of binding relationship between miR-19a-3p and the predicted two sites on TEK mRNA 3'UTR. D. The 3'UTR reporter assay results showing the positive binding between miR-19a$3 p$ and TEK mRNA 3'UTR in HEK293T cell. E. miR-19a-3p expression in our collected LUAD and healthy lung tissues. ${ }^{*} \mathrm{P}<0.05,{ }^{*} \mathrm{P}<0.01$, compared with normal tissues using $t$ test. $F$. miR-19a-3p expression in our selected cell lines. ${ }^{*} P<0.05,{ }^{*} P<0.01$, compared with $B E A S-2 B$ cell line using one-way ANOVA method. $G$. The relationship between TEK mRNA level and miR-19a-3p level in LUAD tissues. $H$. The transfection efficiency of mimic and inhibitor was confirmed by $\mathrm{qPCR}$. ${ }^{*} \mathrm{P}<0.05$, ${ }^{*} \mathrm{P}<0.01$, compared with blank control group using one-way ANOVA method. 
A

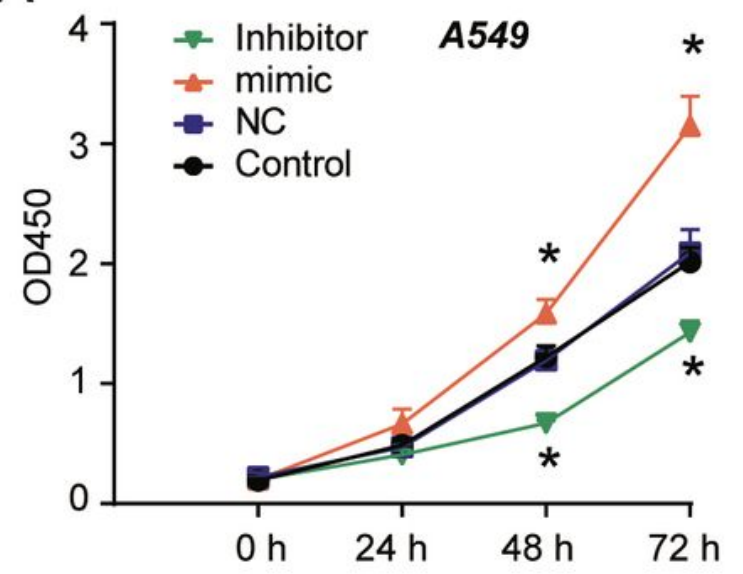

C

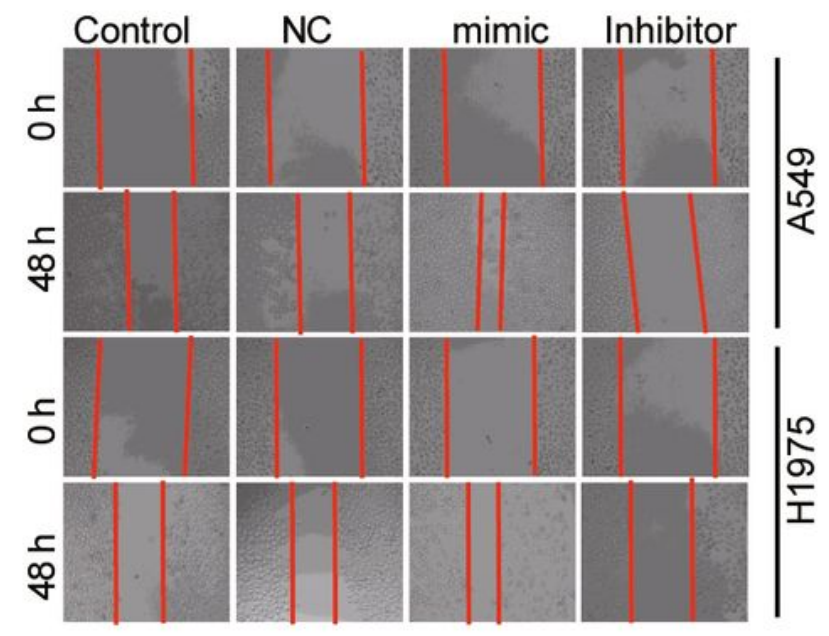

D

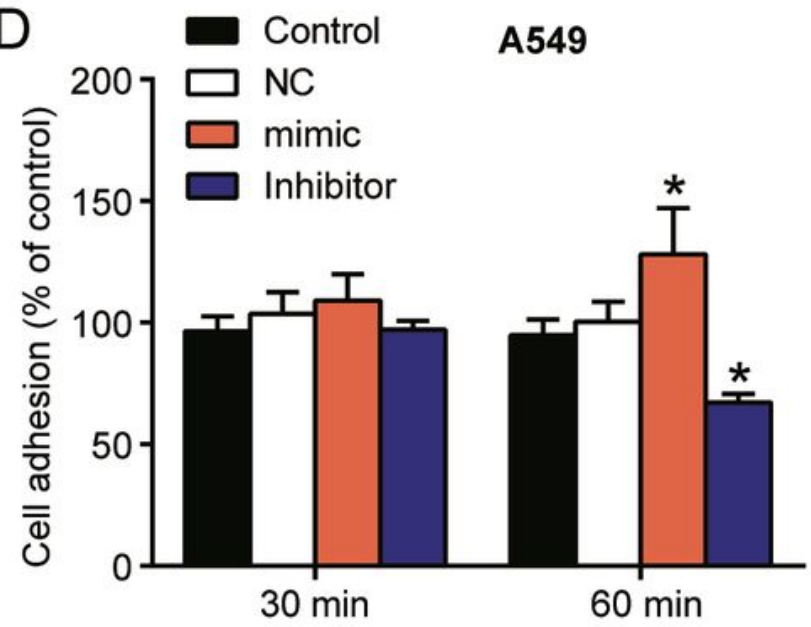

B
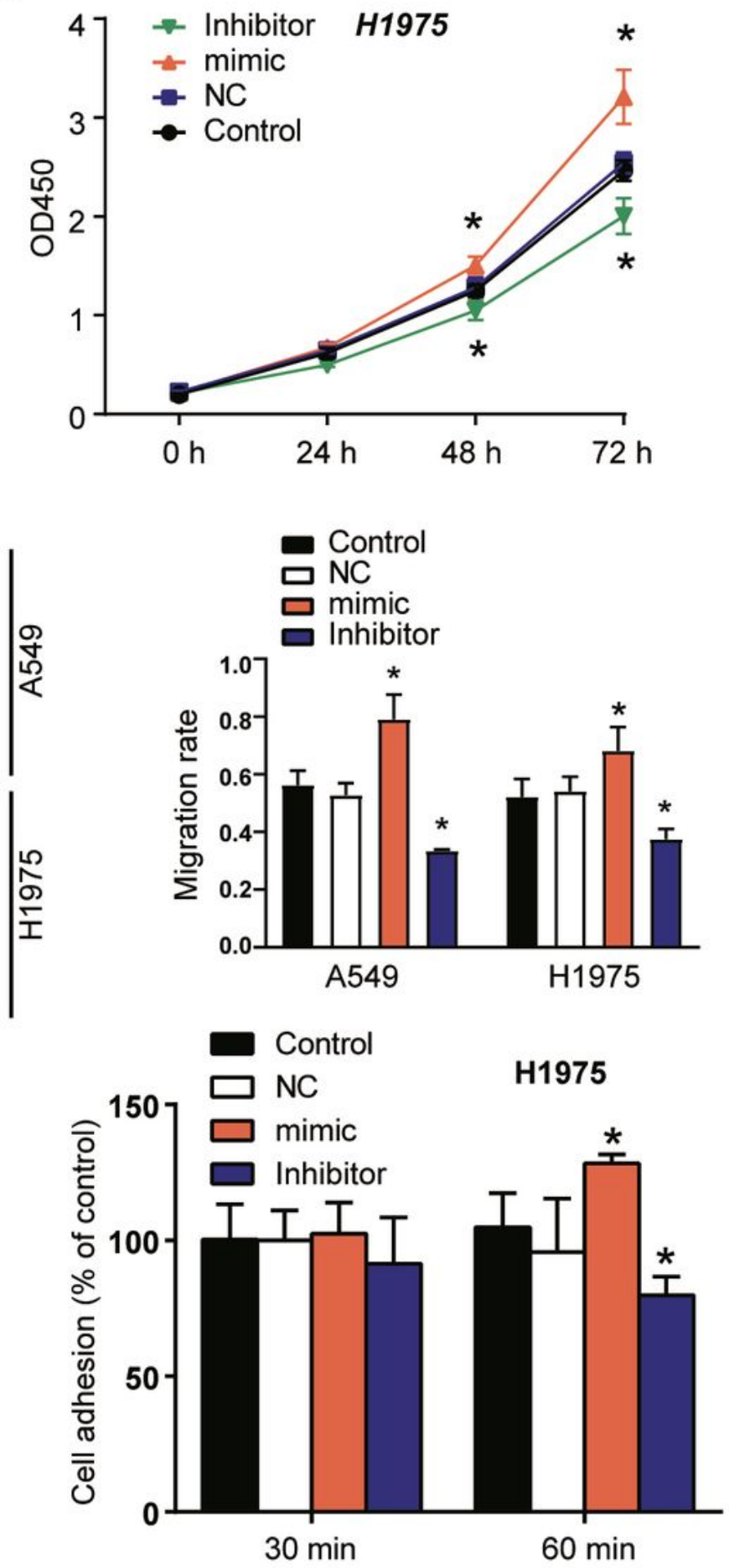

Figure 7

miR-19a-3p promoted cell proliferation, migration and adhesion. A-B. The growth of A549 cells $(A)$ and $\mathrm{H} 1975$ cells (B) during the following $72 \mathrm{~h}$ after transfecting miR-19a-3p mimic and inhibitor was measured using CCK-8 assays. C. Wound healing assay of A549 and H1975 cell lines after transfected with miR-19a-3p mimic and inhibitor for $48 \mathrm{~h}$. The migration rate was calculated as (the distance at $0 \mathrm{~h}-$ the distance at $48 \mathrm{~h}$ )/the distance at $0 \mathrm{~h}$. D. Cell adhesion assay revealed that cell adhesion ability 
increased in mimic group but decreased in inhibitor group 60 min after the cells were plated to the matrix. ${ }^{\star} \mathrm{P}<0.05,{ }^{*} \mathrm{P}<0.01$, compared with blank control group using one-way ANOVA method.
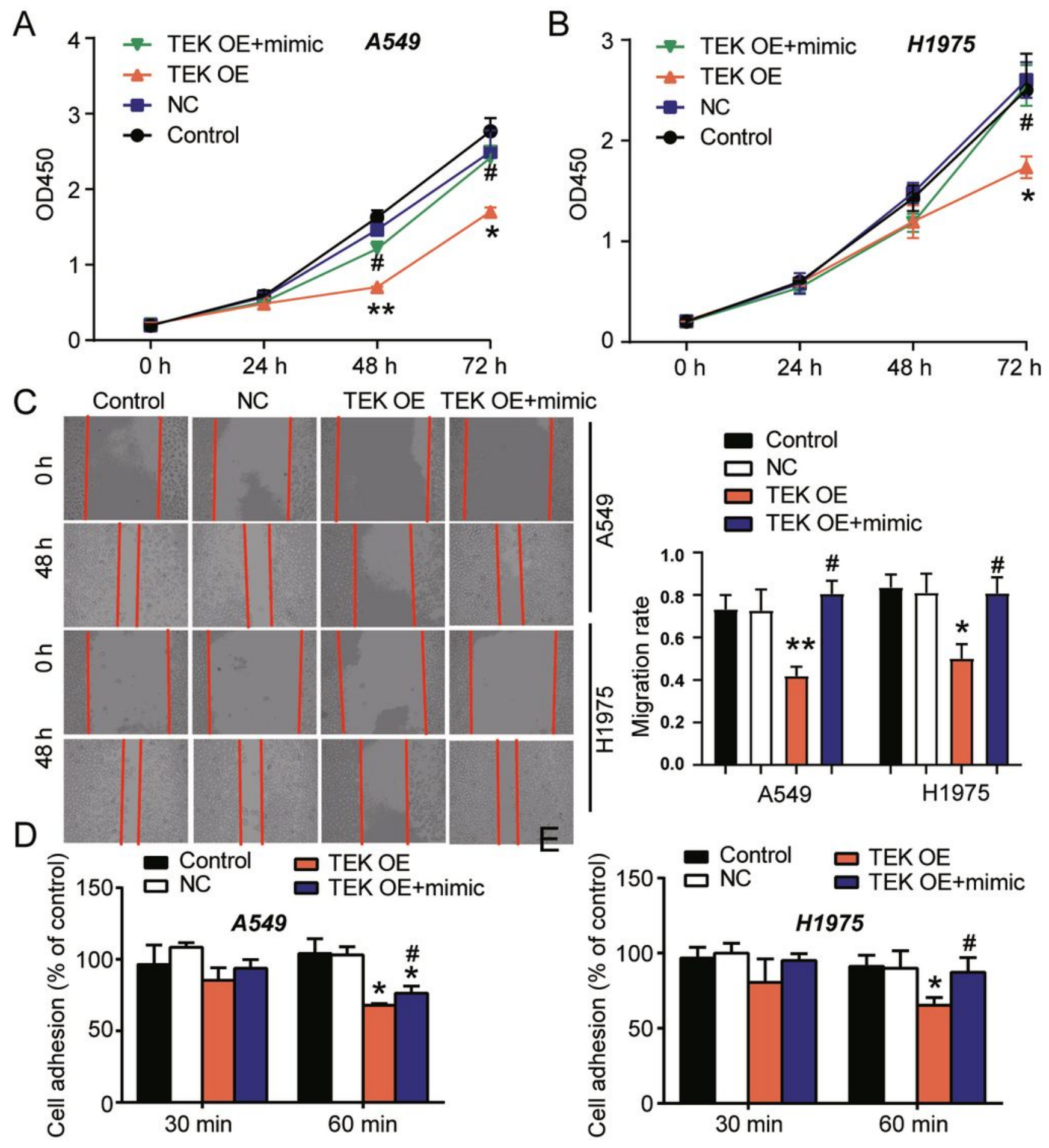

\section{Figure 8}

miR-19a-3p reversed the effect of TEK overexpression on cell proliferation, migration and adhesion. A-B. CCK8 assay results: miR-19a-3p mimic transfection reversed the effects resulted from the transfection of TEK overexpression plasmids on cell proliferation. C. Scratch assay results: miR-19a-3p mimic 
transfection reversed the effects resulted from the transfection of TEK overexpression plasmids on cell migration. D-E. Cell adhesion assay results: miR-19a-3p mimic transfection reversed the effects resulted from the transfection of TEK overexpression plasmids on cell adhesion. 